\title{
A Research on Sorting Machine
}

\author{
S.Siva Sai Kumar Reddy, R. Puviarasi, S.R.Boselin Prabhu
}

\begin{abstract}
Presently a days composing of materials in junk enterprises area unit created manually. There may be chance of mistakes in composing. We have actualized solution for displacement human via programmed management while not manual power. The venture identifies the objects of varied materials and isolates in 3 numerous boxes. By use of sensors diminishes the mistakes in composing and reduces the person power. The planned framework includes metal symbol, IR sensor, smaller than usual cutoff switch for police investigation weight and for composing reason straight movement electrical actuators area unit used. principally in enterprises they utilize transports for moving things beginning with one place then onto ensuing place. therefore we tend to factory-made a transport for moving things by utilizing dc engine then sensors is joined or placed on the conveyor. Actuators area unit place in such a form as AN entree technique.

The management activity of actuators, engines and sensors is incorporates 3 sections Perception, handling and activity. By and enormous, the preceptors area unit sensors mounted on the transport, getting ready is finished by the on-board microcontroller or processor, and also the activity is performed utilizing engines and electrical barrel.
\end{abstract}

Keywords:- Sorting, Conveyor Belt, color, shape, Fruit and vegetable sorting, Visualize tracking.

\section{INTRODUCTION}

The sensors and actuators area unit controlled by exploitation PIC16877A microcontroller (or) arduino (or) raspberry pi3. At the purpose once the detector detects thefabric involved the mechanism impels as indicated by program that's drop within the controller. The actuators area unit activated by utilizing hand-off interfacing board that gets the contribution from controller and yields to the actuators. The sensors area unit related to the controller by utilizing transfer to keep up a strategic distance from the exchanging issues. The engine shaft is related to the roller and also the transport line is ready on the roller these offers nice strain over the belt. The transport engines input gains from electrical device. the ability circuit includes of PIC improvement board, relay interfacing board, electrical device, input interfacing board, DC motors. The explanation utilised for sensors for recognizing materials is completed in program by weight and inductive means that it's organized as metal. By weight and reflection it's organized as glass and if simply reflection it's recognized as plastic. the fabric sorter has been planned in such some way it will satisfy all of the wants of the bundling enterprises wherever results of varied materials area unit factory- made. It's unnumbered application like trash businesses, bundling fields. The venture consists such will deliver high potency and may type materials while not smashup. By this bundling framework finally ends up perceptibly easier.

\section{Types Of Sorting Machines:-}

- $\square$ Multiple Fruit and Vegetable Sorting Machine

[1]

- $\quad \square$ Based On Colour by Pick and Place [2]

- $\square$ Development of Waste Sorting Machine [3]

- $\quad \square$ Material Sorting

- $\square$ Fresh Sea Cucumber Weighing Sorting Machine

\section{MULTIPLE FRUIT AND VEGETABLE SORTING MACHINE}

India could be a farming country with expansive farming [1] produce. Different types of leaved foods area unit created systematically. All the farming manufacture should be organized and reviewed, and lion's share of it's done through physical work. Physical work makes completely different problems like subjective reviewing, repetitive work, irregularities, and low gain. The overwhelm in majority of the higher than problems will be restricted utilizing machine vision. The composing framework utilised as a vicinity of various sustenance handling business types utilizing one amongst the incidental highlights like shading, shape, weight and size and it needs specific condition for its effective operating. The inspiration shade of the transport framework ought to be of specific shading for easy division of the particular natural product from its expertise, legitimate lighting, and a superior camera. The qualities for reviewing should be physicallysustained into the framework before the evaluating method. Section II includes the fabric enclosed, Section III the distinctive shading models and therefore the calculation utilised, Section IV the trial results and Section $\mathrm{V}$ the conclusion and therefore the future extension [1].

Revised Manuscript Received on August 14, 2019.

S.Siva Sai Kumar Reddy, Student, Saveetha School Of Engineering, SIMATS, Chennai, Tamilnadu, India.

Dr. R. Puviarasi, Asst.Professor, Saveetha School Of Engineering, SIMATS, Chennai, Tamilnadu, India.

Dr.S.R.Boselin Prabhu, Associate Professor, Department Of Electronics And Communication Engineering, Surya Engineering College, Mettukadai, India. 


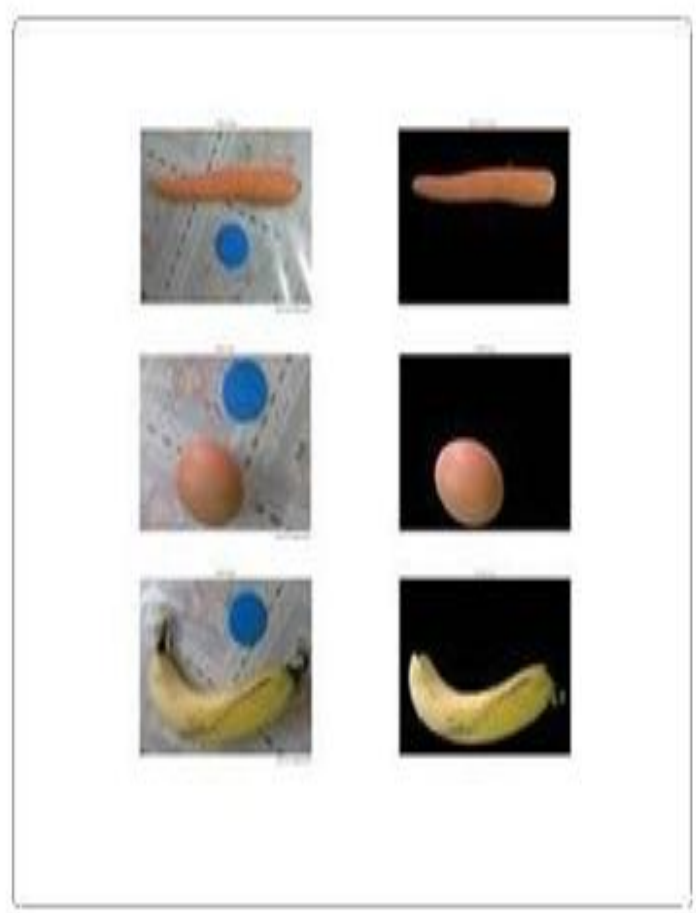

Fig-1

\section{BASED ON COLOUR BY PICK AND PLACE}

Robot could be an elementary half in computerizing [2] the pliant collection framework that one very standard these days. Robots square measure presently quite a machine, as robots have was the arrangement while not bounds as value work wages and purchasers request. Despite the actual fact that the value of obtaining mechanical framework is incredibly pricey nevertheless because the gift quick advancement and a charm in quality with International customary Organization (ISO) principles, human don't seem to be from now on ready to try to such requests. Innovative work - of future robots is moving at AN exceptionally quick pace thanks to the continuously enhancing and overhauling of the standard models of product. Robot and robotization [2] is employed with a selected finish goal to succeed human to play out those undertakings that square measure customary, perilous, complicated and in unsafe region. In an exceedingly universe of leading edge innovation nowadays, automation builds creation capability, enhance item quality and lower generation value. there is nothing a lot of required than few people to program or screen the computer and complete routine maintenance. This paper goes for utterly robotized material coping with framework. this could be doable by utilizing one or two of IR sensors interfaced with AT89S52 small Controller Unit. It synchronizes the event of automatic arm to select the things continuing onward a transport line. It points in characterizing the shaded things that square measure going ahead the transport by choosing and putt the articles in its explicit pre-modified place. During this manner taking away the repetitive work done by human, accomplishing accuracy and speed within the work. This mechanism includes shading sensors that detects the protest's shading and sends the flag to the microcontroller. The microcontroller sends flag to eight hand-off circuit that drives the various engines of the mechanical arm to carry the protest and place it within the preset space. In lightweight of the shading recognized, the mechanical arm moves to the predefined space, discharges the protest and returns to the primary position.

\section{DEVELOPMENT OF WASTE SORTING MACHINE}

The joined robust and fluid waste from personal, business, and fashionable sources are alluded to as metropolitan squanders and are oftentimes seen as materials created in urban zones that are unacceptable for encourage helpful utilize, and expected to be disposed of, burned, reused in bound ways that or thought of characteristically squander. Robust squanders are a lot of arduous to consume due to the terribly issue nature of the material as way as creation and physical qualities, crossing an in depth form of mass densities and damp substance, transfer a few wide selection warming esteems (Lee and statue maker, 2000). Squander administration primarily includes the gathering, transport, preparing, reusing or transfer of waste materials, and is likewise completed to recuperate materials from the waste. Squander administration methods shift typically between territories for a few, reasons, as well as quite material, adjacent land utilizes, and therefore the region accessible.

\section{MATERIAL SORTING \& RESULTS}

Presently on a daily basis it's a pattern in economic process to possess robotization altogether ventures. Mechanization in composition frameworks expands exactness, spares work price and time. composition frameworks are of various like transport framework, choose and place machine- controlled arm so forth. The composition processed during this paper is transport composition framework that utilizes raspberry pi to type the crates. Raspberry pi utilizes the camera with 5MP to catch the image and translate it

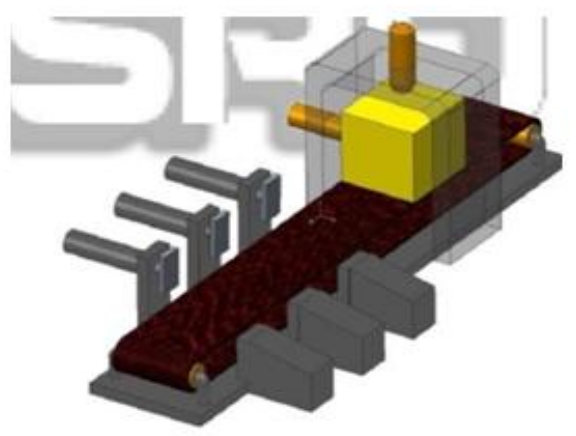

Fig-2 


\section{FRESH SEA CUCUMBER WEIGHING SORTING MACHINE}

Ocean cucumber reproducing territory of China is $112468 \mathrm{hm} 2$ in 2008, the yield are 925.67 million tons, the yield esteem is quite one hundred fifty billion yuan. In any case, this things are basically wont to quantify the heavier load, and have low weight exactitude for the littler load. The modification of standard creation techniques will implausibly enhance the extra estimation of things and potency, diminish work expenses, and serve the neighborhood economy higher.

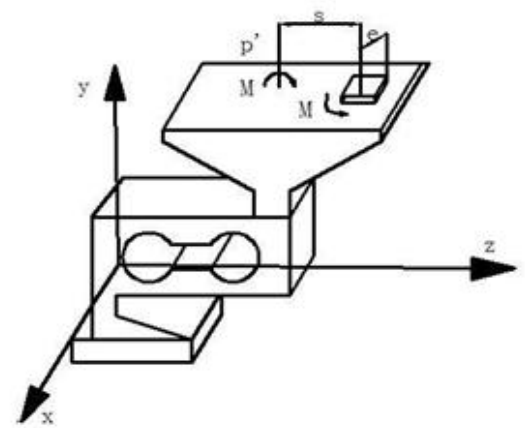

Fig-3

\section{VII.CONCLUSION}

The present framework will simply distinguish eight distinct organic merchandise or vegetable at one conceivable time. To expand the amount of organic merchandise distinguished the highlights removed need to be more and more and affiliation between these highlights ought to be created. One technique for accomplishing this can be through hereditary calculation and learning procedures that might empower it to require in a very specific natural product. A2other system which will be utilised is Associate in Nursing electronic nose as a tangible data. This could tremendously diminish the requirement to get rid of to boot includes as every foods adult from the bottom ousts distinctive chemicals and afterward may be utilised for the ID of the ivied foods likewise lessens the room for the handling the highlights. Consolidating these 2 parameters of we will build up a detailed imbecile proof organic product composing or vegetable composing system. We have projected a framework which might expand the creation rate and preciseness of fabric taking care of frameworks. The framework would isolate objects in light-weight of their type i.e. metal or non-metal, weight and shading by the consumer. Utilization of PLC with the sting of principle doors can build program alteration easy and during this method, we will modify the framework as indicated by the requirement.

\section{REFERENCES}

1. Mathew George, "Multiple Fruit and Vegetable Sorting System Using Machine Vision" George, Int J Adv Technol 2015, 6:1

2. Dharmannagari Vinay Kumar Reddy, "Sorting of objects based on colour by pick and place robotic arm and with conveyor belt arrangement" ISSN 2278 -0149 Vol. 3, No. 1, January 2014

3. Mahmudul Hasan Russel, Mehdi Hasan Chowdhury, Md. Shekh Naim Uddin, Ashif Newaz,Md. Mehdi Masud Talukder,"Development of Automatic Smart Waste Sorter Machine" International Conference on Mechanical, Industrial and Materials Engineering 2013 (ICMIME2013) 1-3 November, 2013, RUET, Bangladesh. 